\title{
ssuons IBERO-AMERICANOS
}

\section{"Café con piernas" una pornotopía a la chilena: sexualidad y espacio en una instalación neoliberal}

\author{
"Café com pernas" uma pornotopia chilena: sexualidade e espaço numa instalação neoliberal \\ "Café con Piernas" a Chilean pornotopia: sexuality and space in a neoliberal installation
}

Marcela Carolina Hurtado Rubio ${ }^{1}$ Rodrigo Francisco Browne Sartori ${ }^{1}$ ${ }^{1}$ Universidad Austral de Chile. Valdivia, Región de los Ríos, Chile.

\begin{abstract}
Resumen
Este trabajo busca analizar el fenómeno de los cafés con piernas ${ }^{1}$ desde la perspectiva farmacopornográfica planteada por la filósofa Beatriz Preciado en sus libros Testo Yonqui (2008) y Pornotopía (2010), entendiéndolo y adaptándolo como parte de un subproducto de la instalación radical del sistema neoliberal en Chile, durante la dictadura militar de Augusto Pinochet y sus directas consecuencias en los gobiernos democráticos que le sucedieron.
\end{abstract}

Palabras clave: Café con piernas. Farmacopornográfica. Chile neoliberal.

\section{Resumo}

Este trabalho busca analisar o fenômeno dos cafés com pernas desde uma perspectiva farmacopornográfica proposta pela filósofa Beatriz Preciado em seus livros Texto Yonqui (2008) e Pornotopia (2010), entendendo-o e adaptando-o como parte de um subproduto da instalação radical do sistema neoliberal no Chile, durante a ditadura militar de Augusto Pinochet e suas consequências diretas nos governos democráticos que o sucederam.

Palavras-chave: Café com pernas. Farmacopornografia. Chile neoliberal.

\begin{abstract}
This work aims to analyze the café con piernas phenomenon from a pharmacopornographic perspective proposed by the philosopher Beatriz Preciado in her books Testo Junkie (2008) and Pornotopia (2010), understanding and adapting it as a part of a by-product of the radical installation of the neoliberal system in Chile during Augusto Pinochet's military dictatorship, and its direct consequences on the democratic governments that succeeded it.
\end{abstract}

Keywords: Café con piernas. Pharmacopornography. Neoliberal Chile.

\footnotetext{
1 Los Cafés con piernas son cafeterías atendidas por mujeres vestidas con bikinis o mini-vestidos, de vidrieras cerradas o semi-abiertas, ubicados en el centro de la ciudad, que funcionan entre las 8 de la mañana y las $19 \mathrm{hrs}$. Algunas de sus particularidades: los clientes son en su mayoría hombres, las trabajadoras mantienen contacto cercano y directo conversando y/o coqueteando con ellos, en ciertos locales se puede, además, optar por servicios sexuales.
}

dados biográficos dos autores_biographical data of the authors 


\section{Introducción}

La hipótesis que sustenta esta investigación afirma que el café con piernas chileno actúa como pornotopía, constituyéndose en un dispositivo farmacopornográfico y transformando un espacio de transición -como la cafetería- en una prótesis semiótica en la cual se teatralizan las interacciones de género y se concretan las mercantilizaciones de los cuerpos femeninos y masculinos y sus respectivas performances. La pornotopía, según Preciado y siguiendo a Michel Foucault (1979), es un lugar de excepción sexual. En este tipo de heterotopía -heterotopía sexual-se alteran las relaciones esperables entre forma y función. Estos espacios, entonces, pueden contener y ser una escisión a la regla moral y el lugar.

La idea de este trabajo, por tanto, es analizar y situar el fenómeno de las mercantilizaciones de la representación corporal en un ejemplo de pornotopía a la chilena, entendiéndolo como un subproducto propio de modelos neoliberales y como paradigma de su impacto en un Chile pionero en este tipo de sistemas políticos a nivel sudamericano. En este ámbito, la pornotopía surge como un dispositivo de exclusión sexual que recae directamente en los cuerpos y -en el caso del Chile de la dictadura y de la postdictadura- en los cuerpos de las "mujeres objetos" que trabajan en los cafés con piernas y que son víctimas de la triada cuerpo, espacio y contrato. Vicio pornotópico que hacen que este espacio de negocio se torne en un ejemplo único en América Latina y ajustado al Chile que nace bajo el alero de los Chicago Boys ${ }^{2}$ y sus secuaces, aliados con la dictadura de Augusto Pinochet y que -como modelo económico político- perdura durante los gobiernos posteriores de transición hasta la actualidad. Para Nelly Richard (2001, p. 227), "los gobiernos de la 'transición' democrática se dedicaron sobre todo a re-agenciar la continuidad de los efectos ya delineados por la ofensiva neoliberal de la dictadura que conjugó represión (la violencia militar) con modernización (las políticas de consumo del mercado y la televisión)".

En esta línea, fue necesario distinguir las características del fenómeno pornotópico en dos ciudades de Chile: Santiago (capital y centro del país) y Valdivia (ciudad del sur austral), a través de las cualidades observables en tres cafés con piernas de cada una de las ciudades. La intención fue caracterizar los

\footnotetext{
2 Para mayor información sobre la influencia de los Chicago Boys en Chile, revisar el documental "Chicago Boys - Ellos crearon el Chile en que vives" (2015) de Carola Fuentes y Rafael Valdeavellano.
}

mecanismos de producción de representación corporal. Como herramienta metodológica, esta tarea se realizó con una matriz de análisis que contiene elementos de la teoría farmacopornográfica con algunas nociones provenientes de la teoría arquitectónica, la comunidad, los estudios de género, la comunicación y la etnografía. Asimismo, se examinaron las condiciones espaciales que facilitan la instalación del fenómeno, en tanto, teatralización de las interacciones de género y sus estereotipos occidentales.

En la primera fase del trabajo de campo se realizó: una clasificación y caracterización de tipos de locales y un análisis de las interacciones espacio-sexuales que operan en ellos. Dentro de los hallazgos más notables se puede mencionar: el anonimato como signo más visible del fenómeno, pues el espacio busca resguardar las acciones e identidad del cliente y trabajadora y la relación entre las dimensiones espaciales y las prestaciones sexuales, más la escenificación y teatralización ${ }^{3}$ de las relaciones corporales y de género.

Cada lugar tiene sus patrones de entrada y salida de personajes-mujeres-cuerpo, en los cuales los varones son espectadores-actores ya que entran en el territorio de una trabajadora determinada. Siguiendo a Le Breton (2004) se puede decir que la simbólica corporal se repite en todos los cafés: saludo-beso, exposición, elección del servicio, atención y salida. Así como los patrones de uso del espacio en relación a los contratos y prácticas sexuales -si las hay-.

\section{Revisión teórica}

Dicho lo anterior, se pretende profundizar en la tarea de dar cuenta de este fenómeno, de la representación corporal y del cuerpo como objeto farmacopornográfico a nivel nacional y local. Para ello, es necesario atender al cuerpo humano como un dispositivo biopolítico (Foucault, 1995; Hardt \& Negri, 2000; Preciado, 2008 y 2010). Es decir, un espacio donde las transacciones económicas que sostienen el sistema capitalista puedan ser subvertidas. Pero, para que esto ocurra, el proceso (como conjunto de etapas sucesivas de un fenómeno artificial) y los procedimientos (método para ejecutarlo) mediante los cuales se desarrolla, deben ser develados a través de la descripción de lo que se concibe como femenino y masculino.

3 Se entiende, en este contexto, la teatralización en tanto puesta en cuerpo y la escenificación en tanto puesta en espacio. 
Partiremos de los siguientes supuestos:

a. El cuerpo como representación será entendido como cuerpo canonizado (un modelo de corporalidad a seguir) que está intervenido por técnicas médicas, farmacológicas y sociosemióticas; que cambia y se modifica según la necesidad, pues esta es la única manera de ser agente activo en la sociedad y la economía. En la sociedad neoliberal, las intervenciones corporales, que se encuentran dentro del canon, son esperadas y bienvenidas como parte de la construcción del cuerpo humano contemporáneo (Le Breton, 1999; Duch \& Mélich, 2005; Bauman, 2008; Preciado, 2008; Despentes, 2009; Nancy, 2003; Taussig, 2008; Hurtado, 2010). En el caso especial de Chile-como paradigma neoliberal- el cuerpo se traslada de un cuerpo vigilado y dañado por la violencia militar como sujeto violentado- a un cuerpo digno de consumo (objeto) que, según Richard (2001), funciona como horizonte de gratificación consumista y cuya referencia se percibe en la dócil sumisión de la mujer en el espacio de los cafés con piernas.

b. La argumentación de Preciado (2008) al aseverar que los cuerpos en las sociedades contemporáneas occidentales estarían siendo mediados por técnicas sociosemióticas - como la pornografia ${ }^{4}$ - y biomédicas - como la farmacología ${ }^{5}$ - es parte crucial de la fundamentación teórica de este trabajo. Por cuanto se entenderá que los cuerpos chilenos, urbanos y contemporáneos, de algún u otro modo, están siendo mediados, controlados y delimitados por las técnicas pornográficas y/o biomédicas. Para llegar a esta noción se requiere entender una serie de procesos políticos, económicos, sociales y de las ciencias biológicas a los que se recurre para el análisis de discursos de autores de variadas disciplinas que han incursionado en estos temas (Preciado, 2002, 2008, 2009, 2010; Deleuze \& Guattari, 2005; Derrida, 1997; Bauman, 2008; Foucault 1967, 1979, 1995, 2007, 2008a, 2008b; Silva Echeto \& Browne, 2004 y 2007; Illanes, 2010; Montecinos, 1996, 2005; Sánchez, 2005).

c. La situación en Chile se presenta a partir de la instalación del modelo neoliberal y debe, a su vez, ser entendida en el contexto de lo que ello implicó

\footnotetext{
${ }^{4}$ El concepto de pornografía es entendido como cualquier dispositivo sociosemiótico que genere el mecanismo de excitaciónfrustración-excitación.

5 El concepto de farmacología es entendido como cualquier dispositivo farmacológico químico que actúe como mecanismo de control social (por ejemplo, el Modafinilo que es una droga utilizada por estudiantes para mantenerse despiertos durante largas horas y que fue inventada para el ejército norteamericano en su intervención en Afganistán).
}

para el ámbito latinoamericano, donde los procesos siempre se superponen y se hace difícil marcar inicios y términos cronológicos, a diferencia de Europa y Estados Unidos, donde es factible distinguir un marcaje a propósito de las guerras mundiales y sus derivas posbélicas que llevaron a una nueva forma de organizar la sociedad (Neira, 2005; Browne, 2009; Hardt \& Negri, 2000). Por el contrario, en Chile los procesos y las representaciones corporales contemporáneas coexisten con otras (moderna, colonial, indígena, negra, migrante). Es necesario, por tanto, recalcar que la representación corporal chilena ha variado profundamente en los últimos cincuenta años, décadas en que el país transitó por una serie de modelos políticos y económicos provenientes del primer mundo. En consecuencia, hoy en día no se podría hablar de una representación corporal propiamente tal, sino de construcciones que mutan de la mano de estos procesos sociales (Illanes, 2010; Sánchez, 2005; Montecinos, 1996, 2005) que han determinado y marcado al cuerpo nacional con rasgos farmacopornográficos fusionados con elementos locales, donde el punto que no cambia - desde las década de los '70- es, radicalmente, la cuestión del consumo y la mercantilización tan caros a la neoliberalización de los cuerpos y a sus más variadas formas de "instrumentalización burocrática y de operacionalización técnico-profesional" (Richard, 2001, p. 232).

d. En el período de postdictadura, el tratamiento de la corporalidad cambió rápidamente, por lo menos en cuanto a las imágenes, y abrió el debate público a temas de índole sexual, erótico y de género. A este respecto, la imposición del modelo económico comenzó a influir en las corporalidades y sus interrelaciones, puesto que el libre mercado comienza a liderar la independencia del género y/o la sexualidad, ya que, si se es capaz de generar excitación, entonces también se está capacitado para producir un determinado capital sexual.

e. El concepto pornotopía planteado por Preciado (2010) es revisado como un espacio de alteración de la norma y -en este contexto- se entenderá como heterotopias sexuales en tanto lugares de excepción que constituyen "brechas en la topografía sexual de la ciudad, alteraciones en los nodos normativos de codificación de género y la sexualidad, las prácticas del cuerpo y los rituales de producción de placer" (Preciado, 2010, p. 121).

\section{Cafés con piernas}

En este contexto y como ya se adelantó, un lugar paradigmático es el café con piernas, donde se ofertan 
cuerpos femeninos semidesnudos a la vera de una barra y un café. El escenario es más o menos el mismo en todo Chile, un espacio en el centro de la ciudad con vidrieras de vidrios oscuros o cubiertos desde las rodillas de la trabajadora hacia arriba. Dentro del local se encuentran mujeres poco vestidas que sirven café en una barra delgada de no más de treinta centímetros de ancho. Las mujeres detrás de la barra se encuentran en una plataforma de quince a veinte centímetros de alto. Un escenario en el que las meseras se desplazan para ser vistas por los asistentes al local. Con esto se privilegia que los clientes centren su mirada entre la pelvis y el busto de las trabajadoras que sirven café.

El fenómeno chileno café con piernas aparece tímidamente en los sesenta, con los cafés Haití y Caribe en el centro de Santiago, capital del país, pero no es hasta mediados de los ochenta en que se desarrollan como un negocio rentable con sus propias reglas de producción y consumo. En los primeros años, las mujeres que atendían el local usaban (y hoy siguen la tradición) vestidos cortos ajustados y tacones altos. La segunda etapa aparece con el éxito del café Barón Rojo, lugar donde las mujeres cambiaron los vestidos por pequeños bikinis o conjuntos mínimos de ropa interior que mostraban más aún su cuerpo con el atractivo extra de un momento llamado "el minuto feliz". En ese momento, las meseras se sacaban el brasier/sujetador durante sesenta segundos. Por otro lado, la década de los ochenta y noventa en Chile está marcada por la dictadura y posterior vuelta a la democracia y su institucionalidad. Este proceso implicó una transición de todos los modelos sociales. En ese escenario, se puede afirmar que el fenómeno realmente explota como una vía de escape aceptada y reconocida en el ámbito de una sociedad y en el marco de una dictadura/postdictadura reaccionaria y conservadora. Un pequeño destape, una contenida liberalización de las costumbres, siempre dentro del límite heteronormativo y dando pie a un reconocimiento patriarcal de fuerte acento en el machismo chileno-criollo.

Ahora bien, los dispositivos farmacopornográficos aparecen dentro de las arquitecturas interiores de estos locales, en las relaciones entre clientes y meseras, así como los mecanismos que han logrado dar continuidad temporal al negocio. En relación a estos espacios se puede mencionar el rol indispensable del juego visual. Por ejemplo, si se sigue el recorrido visual de un cliente, la apariencia exterior anunciará, sin mostrar, lo que hay en su interior. Una vez dentro, el lugar estará inundado de espejos y, dependiendo de la inversión comprometida, éstos serán de mejor calidad o tendrán un diseño temático (futurista, barco tropical, tradicional, etc.). Para Da Silva Concha, esta es la base del juego simbólico "entre el afuera: vidrio/separación, y el adentro: espejo/acceso visual total" (Da Silva Concha, 2008, p. 234).

Este lugar se constituye como un espacio masturbatorio (que genera ciclos de excitaciónfrustración-excitación) en los cuales la masculinidad puede servirse de una feminidad sexualizada y donde, por un costo relativamente bajo, se pueden comprar unos segundos de un cuerpo mujer vivo y servil que, como y con forma de café, contiene un simulacro de masculinidad/feminidad (De Lauretis, 1993; Butler, 2005; Haraway, 2004) que satisface. Es en este escenario de vidrio, espejos y tarima, en el cual los hombres pueden acceder a una categoría de mujer, no a la mujer en el sentido real, sino que a un imaginario donde lo femenino se traduce en un ser sexual, receptivo, dispuesto y servil (Colomina, 2013 y 2010). De este modo se puede comprobar que el acceso visual a la mujer es un privilegio masculino, está normado y cataloga lo permitido/visible y lo prohibido/no visible.

Lo visible en el café con piernas se puede configurar en variadas interpretaciones. Así aparece la mujer objeto de deseo, consejera, receptora del diario vivir del cliente (sin el riesgo del juicio o las consecuencias de los comentarios masculinos), lo que da lugar a un simulacro de la relación de pareja heterosexual. Es interesante como lo femenino queda detrás de la barra: un escenario más alto físicamente, pero servil, expuesto y receptivo, una especie de epígrafe de la noción de lo femenino en Chile. Un país donde el femicidio cobra vidas y la maternidad es una institución. Este juego de oposición -sin sentidoparece construir la representación del cuerpo-mujerchileno, por ello el carácter pornotópico neoliberal de esta iniciativa que se concibe desde el nacimiento de una nación pro-consumo y mercado ${ }^{6}$.

Por tanto, el juego cliente-mesera se establece como una relación urbana dentro de un espacio cerrado, espacio que al no tener sillas facilita el tránsito del cliente-macho. En Santiago, estos cafés están pensados para la hora de colación. Para una parada entre un trámite y otro, como una distracción de acción

\footnotetext{
${ }^{6}$ Un buen ejemplo de lo mencionado es el regalo que la Asociación de Exportadores y Manufacturas de Chile, en el año 2017, le hace al Ministro de Economía del gobierno del empresario Sebastián Piñera, Luís Felipe Cespedes: una muñeca inflable con el fin de "estimular la economía". Mayor información en: https:// www.biobiochile.cl/noticias/economia/negocios-y-empresas/ 2016/12/13/que-hace-una-muneca-inflable-junto-al-ministro-deeconomia-en-cita-con-empresarios.shtml
} 
visual, por lo general, que entretiene el devenir formal de una jornada de trabajo y varios compromisos. Esta pornotopía responde a la necesidad de los hombres chilenos de reafirmar una identidad masculina colectiva, en la que se puede acceder a un espacio más privado que el del trabajo, pero más público que el de la casa, conformándose así una teatralización de las interacciones de género, una manera del ser hombre menos exigente que la del cotidiano y donde, además, ellos son protagonistas. El café remeda la estructura del imaginario tradicional chileno, donde el hombre llega al hogar en su momento de distensión y la mujer se encuentra en la domesticidad, esperándolo, servil y dócilmente.

Los escenarios del país cambiaron, las mujeres de todos los estratos sociales comenzaron a trabajar fuera de la casa y los hombres han debido adaptar los modelos de masculinidad aprendidos. En ese quiebre aparecen estos locales y se convierten en una especie de prótesis semiótica que permite al varón chileno seguir viviendo dentro de una masculinidad delimitada, conocida y deseada. El juego del café es poder ejercer una masculinidad sin consecuencias, no hay rechazo, tampoco aceptación, se puede mirar y comentar, pero sin tener que responder físicamente; con el beneficio de que es un negocio legal, permitido y -a estas alturasuna institución de la cultura nacional chilena.

Para las mujeres jóvenes que acceden a este oficio significa una posibilidad de incrementar sus ingresos económicos. Lo que, en algunos casos, les permitirá ser autovalentes sin tener que, por ejemplo, transgredir la ley. También les permite reafirmar su feminidad en el mercado masculino (mujer joven deseable). Además se convierten en protagonistas. En ese pequeño escenario: la tarima, pueden jugar a ser reinas de seducción y belleza, aunque sólo sea por el tiempo de su turno de trabajo. Estos locales permiten a los hombres acceder a los múltiples roles masculinos según su propia necesidad: el seductor, las ritualizaciones masculinas (por ejemplo, ver los partidos de fútbol acompañados de mujeres que no cuestionarán su comportamiento), reivindicar la potencia sexual (en el caso de jubilados, ancianos, personas con disfunciones sexuales) y otros que necesitan y que pueden acercarse a ellas sólo gracias a este simulacro falocéntrico. En estos espacios se construye una masculinidad mediada por la servicialidad (son atendidos) y domesticidad (el trato es familiar y cercano). Lo femenino, en tanto, se representa por el altruismo y complacencia de las mujeres que atienden, escuchan y acogen amorosamente sin juzgar a sus clientes. De este modo, dice Da Silva
Concha (2008), se mezcla el mercantilismo (aunque quizás sea más apropiado hablar de neoliberalismo) de una empresa y el altruismo servicial esperable en una mujer, según los modelos conservadores de la sociedad chilena.

Un paradigma en este negocio es que la misma mujer responde a modelos opuestos: "la seductora" que exhibe su cuerpo, pero no lo entrega (lo que la acerca a la reina de belleza) y la "decente" que sirve al hombre en su transitar diario (altruismo y servicialidad).

\section{Tipología, caracterización y categorización}

La metodología con la que se llevó a cabo el trabajo de campo, buscó recoger datos evidenciables en pautas de evaluación pre-establecidas tales como metros cuadrados, organización de mobiliario, entre otros. Relaciones entre los cuerpos y la de éstos con el espacio por medio de variables proxémicas; entrevistas semi-estructuradas que indagaron en los servicios sexuales prestados, transacciones y reglas no dichas.

Para estos efectos se organizaron tres visitas a la ciudad de Santiago, durante tres días consecutivos, con tres observadores cada vez: en el período comprendido entre enero de 2013 y marzo de 2014. Esta metodología debió ser revisada en cada visita según las condiciones encontradas en los locales seleccionados, logrando así cumplir con el requisito de triangular la información obtenida.

Luego, toda la información se trasladó a instrumentos de análisis en los que se realizó la anonimización de locales, trabajadores y usuarios donde se les asignó un código para identificar las categorías que se establecieron dentro del proyecto por la diversidad de expresiones en los distintos lugares. En consecuencia, fue determinante distinguir cuatro grandes grupos -en adelante tipologías-, que se explican a continuación:

\section{Tipologías de los cafés con piernas}

\section{a. Café tipo 1}

Responden a los patrones de su aparición en los años ochenta. Se pueden ejemplificar en los cafés Haití y Caribe. Los servicios prestados son los de una cafetería tradicional, pero se le agrega la cualidad espacial de una barra donde las trabajadoras están entre 15 y 30 centímetros por sobre el cliente. 
En tanto, el cliente tiene la posibilidad de establecer una conversación con la trabajadora, servicio que luego debe ser cancelado en forma de propina.

Las trabajadoras usan un vestido corto y tacones muy altos. Se desplazan mostrando su corporalidad, dejando que los clientes del lugar las observen desde el otro lado de la barra. Las trabajadoras tienen contrato de trabajo estable y los beneficios son los establecidos en el Código del Trabajo.

\section{b. Café tipo 2}

Se pueden encontrar en calles principales pero los vidrios que dan hacia la vereda están tapados y sólo se deja ver la zona media baja de la trabajadora. Estos locales también son habituales en los pasajes interiores del centro de Santiago, capital del país.

Las condiciones de espacio son similares a las descritas anteriormente, salvo en la iluminación. Se caracterizan por tener luces de neón, espacios oscuros. En general, son locales con menor cantidad de metros cuadrados y cuentan con dispositivos audiovisuales.

Las mujeres lucen pequeños bikinis, tacones altos y se pasean por detrás de la barra y por todo el local. Los servicios ofrecidos, además de los de una cafetería tradicional, consideran abrazos, roces y conversaciones que incluyen temas sexuales que puedan desatar en el cliente el ciclo de excitación. En estos lugares los servicios son pagados por anticipado. Al obtener el ticket del servicio, el cliente puede acceder a la trabajadora escogida. Sin embargo, el consumo de los productos de cafetería tiene otra forma de operar: se paga al terminar como en cualquier otro lugar y se recibe una boleta. Las mujeres reciben propinas de los clientes y tienen contratos de trabajo del mismo modo que en el Café tipo 1.

\section{c. Café tipo 3}

Mantiene las condiciones espaciales de la barra, a unos 15 o 30 centímetros del suelo para que la zona media baja de las trabajadoras sea expuesta a los ojos de los clientes. Las trabajadoras se mueven por todo el local ofreciendo servicios de orden sexual, sin llegar a la penetración.

Cada cliente puede disponer de más de una trabajadora para su consumo. Los servicios no son de más de cinco minutos y se realizan en el mismo local en zonas menos iluminadas. Para acceder a ello, se debe comprar un ticket con el valor especificado. Las trabajadoras reciben la propina directamente del cliente.
Una característica importante es que este tipo de local sólo se encuentra en pasajes del centro de Santiago. Además, estos cafés son mucho más pequeños que los anteriores y nunca cuentan con más de cinco trabajadoras. Las mujeres tienen un lugar de descanso donde esperan turnos. El servicio de cafetería se paga de la misma manera que en los casos anteriores. No existe información del tipo de contrato.

\section{d. Café tipo 4}

Mantienen todas las características del Café tipo 3 , pero en espacios que no superan los 25 metros cuadrados. Por el tamaño, la barra no opera como divisor de espacio, por lo que las trabajadoras se pasean por todo el local. En estos lugares se ofertan servicios de cafetería y también sexuales.

La diferencia con los otros locales es que una misma trabajadora puede atender a más de un cliente a la vez sin que los usuarios tengan alguna relación entre ellos. El sistema de ticket y boleta es el mismo. En estos lugares se observan las condiciones más precarias de trabajo, pues las mujeres superan las ocho horas de trabajo sin Ley de la silla ${ }^{7}$. La mayoría de las trabajadoras son extranjeras (peruanas, colombianas entre otras nacionalidades) y no queda claro si son mayores de edad o si tienen sus documentos de migración al día.

Reciben propinas de los clientes igual que en los casos anteriores, pero las actividades sexuales se realizan sin importar la iluminación o la cercanía con otra trabajadora o con los clientes que puedan estar siendo atendidos.

\section{Categorización: mercantilización del cuerpo-hombre}

Otra observación relevante que arrojó la investigación fue que las relaciones entre trabajadoras y clientes anunció que también el cuerpo masculino sufre un proceso de mercantilización. Dicho proceso es de otra naturaleza, pero responde a la misma dinámica de transacción sexualizada. En este caso bio-hombres que representan un determinado poder adquisitivo, dentro de este espacio pornotópico neoliberalizado.

La posibilidad de que el hombre adquiriera o no los servicios de un cuerpo (trabajadora) dependerán de la relación que establezca con ella y esta será mediada

\footnotetext{
7 Se conoce como Ley de la Silla una normativa vigente en Chile desde 1914, que resguarda que existan sillas disponibles para los trabajadores en el lugar donde realizan sus labores. Actualmente la ley queda contenida en el Código Trabajo en el Art. 193 Título I perteneciente al Libro II.
} 
por el acercamiento que decida la mujer con respecto al hombre y por la capacidad de compra del sujeto.

Se debe destacar que como cada trabajadora tiene un espacio predeterminado de atención al cliente, este sólo será atendido por la persona asignada a ese espacio. El hombre no decide cual es la mujer que lo atenderá, por ende, no elige al cuerpo-mujer que detonará sus ciclos de excitación-frustración, sino más bien es elegido por quien tiene el dominio de ese territorio.

En relación a la espacialidad de los cafés, se deben hacer notar tres grandes rasgos que determinan las actividades contenidas: 1) Si se encuentra en la calle principal, en un pasaje o galería (espacio público, pero al interior de una edificación); 2) Dimensiones en relación a metros cuadrados; 3 ) escenificación y teatralización del espacio (diseño de la escenografía que representa al lugar). Estas tres características se encuentran relacionadas directamente con los procedimientos corporales, gestiones de la sexualidad y patrones de género.

En el primer punto, la visibilidad del local entra en juego. Al estar en la vía pública con luz natural sólo cabe la posibilidad de tapar el medio superior de la trabajadora y también del cliente. Se tiene conciencia de que se está a la vista de los peatones. En el caso de los lugares dentro de galerías o pasajes la visibilidad es menor producto de la luz artificial y el mayor cierre de ventanales hacia el café. Así, el anonimato del cliente y sus acciones se resguarda. También las acciones y la identidad de la trabajadora.

En el segundo punto cabe destacar que las dimensiones espaciales de los locales y las actividades sexuales en ellas se encuentran estrechamente relacionadas. Hay una relación de: a menor espacio $\left(\mathrm{mt}^{2}\right)$ mayor variedad y cantidad de prestaciones sexuales y a mayor espacio $\left(\mathrm{mt}^{2}\right)$ menos prestaciones y contratos sexuales directos en el local. No se cuenta con información que permita determinar si las trabajadoras ofrecen otros servicios fuera del local y horario de atención.

La escenificación y teatralización de las relaciones corporales sexuales y de género pasa por un primer diseño del lugar: la tarima, espejos y pequeña barra estarán presentes en todos los locales. La presencia de luz natural o artificial determina el paso a un tiempo diferente, con esto se quiere explicar que, al entrar en un espacio con luces de neón, música con volumen alto y mujeres bailando, la sensación es la de estar en un lugar extra cotidiano, fuera del tiempo que habitaba el cliente, quien pasa de la luz día -y sus tránsitos por el centro de la ciudad-a un pequeño "teatro sexualizado".

Cada lugar tiene sus patrones de entrada y salida de personajes-mujeres-cuerpos, donde los varones son espectadores-actores pues entran en el territorio de una trabajadora determinada. La simbólica corporal se repite en todos los cafés: saludo beso, exposición, elección del servicio, atención y salida.

Otro elemento escenográfico de los cafés con piernas es el vestuario de las trabajadoras que tendrá directa relación con la proxémica que establece la mujer con los clientes. Si en los locales de mayor tamaño y con acceso directo hacia la calle se ven mujeres con vestidos cortos, pantimedias y tacones altos, en los interiores están con colaless y brasier y son de colores brillantes, que destacan la piel de las trabajadoras. En los primeros se saluda con un beso o dos y el hombre no pasará de tomar la mano de la trabajadora. En cambio, en el segundo, es ella quien aproxima su cuerpo al cliente. En ambos casos es la mujer quien domina el territorio, pero quien al mismo tiempo mantiene una actitud servicial y ofertante.

De este modo, acceder a algún tipo de servicio sexual dependerá, además del poder adquisitivo, de la visualización que se logre desde el exterior. Mientras menos se vea al interior, más cosas pueden suceder.

Una de las características comunes a todos los cafés y categorías es que no se observan servicios sexuales que impliquen penetración de parte del varón a la trabajadora. Ellas comentan que no son prostitutas y que les cuesta entender por qué los hombres solo van a "ponerse duros". La duda parece plausible en un lugar donde el deseo es un juego de representaciones y, por ende, valen las palabras de Jameson y Strauss:

\footnotetext{
"Esto no es la vida real. Es un gran juego, un gran juego que consiste en follar mentalmente. $\mathrm{Si}$ consigues ponerte a tono con los clientes y deducir, al hablar con ellos, quiénes son y qué están pensando, entonces podrás vencer. Quizá en lo más hondo no seas una persona manipuladora, pero aquí debes manipular. Y si aprendes a hacerlo del modo correcto podrás ganar lo que quieras (Jameson y Strauss, 2005, p. 77).
}

El capital neoliberal de las mujeres, heredado de los modelos dictatoriales y sus consecuencias, no es sólo el cuerpo, sino su capacidad de generar excitación, en este caso frustrante (si se ve desde la perspectiva de lo incompleto del acto sexual). Ahora bien, desde otra mirada, este fenómeno es solamente una posibilidad más que les ofrece el sistema neoliberal 
a las personas, a las mujeres sometidas al clientelismo de la violencia simbólica occidental, otra más pura y dura consecuencia de la oferta y la demanda, la oferta y la demanda del deseo.

\section{Referencias}

BAUMAN, Zygmunt. Modernidad Líquida. Buenos Aires: Fondo de Cultura Económica, 2008.

BROWNE, Rodrigo. De la comunicación disciplinaria a los controles de la comunicación. La Antropofagia como transgresión cultural. Sevilla: Ediciones Alfar, 2009.

BUTLER, Judith. Cuerpos que importan. Sobre los límites materiales y discursivos del "sexo". Buenos Aires: Paidós, 2005.

DA SILVA CONCHA, Davenir. Masculinidad y café con pierna. ¿Crisis, reacomodo o auge de una "nueva" masculinidad?". $L a$ Ventana, n. 27, p. 231-247, 2008.

DE LAURETIS, Teresa. Sujeto excéntrico, la teoría feminista y la conciencia histórica. In: CANGLIAMO, María; DUBOIS, Lyndsay (org.). De mujer a género. Teoría, interpretación y práctica feminista en las ciencias sociales. Buenos Aires: Centro Editorial de América Latina, 1993. p. 73-113.

COLOMINA, Beatriz. Privacidad y Publicidad. España: CENDEAC, 2010.

COLOMINA, Beatriz. La domesticidad y la guerra. Barcelona: ACTAR, 2013.

DESPENTES, Virginie. Teoría King Kong. Barcelona: Melusina, 2009.

DELEUZE, Gilles; GUATTARI, Félix. El anti Edipo: Capitalismo y esquizofrenia. Argentina: Paidós, 2005.

DUCH, Lluís; MÉLICH, Joan-Carles. Escenarios de la corporeidad, antropología de la vida cotidiana 2/1. Madrid: Trotta, 2005.

DERRIDA, Jacques. De la Gramatología. Buenos Aires: Editorial Siglo XXI.

FOUCAULT, Michel. Hercules Barbin (Herculine Barbin llamada Alexina B.). Madrid: Talasa Ediciones, 2007.

FOUCAULT, Michel. Historia de la locura en la época clásica. Volumen II. México: Fondo de Cultura Económica, 1967.

FOUCAULT, Michel. Historia de la sexualidad. 2. El uso de los placeres. Buenos aires: Siglo XXI, 2008b.

FOUCAULT, Michel. Historia de la sexualidad. I. La voluntad de saber. Madrid: Siglo XXI, 1995.

FOUCAULT, Michel. Microfísica del poder. Madrid: La Piqueta, 1979.
FOUCAULT, Michel. Vigilar y castigar. Nacimiento de la prisión. Buenos Aires: Siglo XXI, 2008a.

HARAWAY, Donna.Testigo_Modesto@Segundo_Milenio: HombreHembra_Conoce_Oncoraton. Feminismo y Tecno ciencia. Barcelona: UOC, 2004.

HARDT, Michael; NEGRI, Antonio. Imperio. Cambridge: Harvard University Press, 2000.

HURTADO, Marcela. La provisionalidad del cuerpo posmoderno. In: JUBINI, G.; OLIVA, I. (org.). Discursos y cultura: Miradas a Latinoamérica desde la transdisciplinidad. Valdivia: Ediciones Universidad de Chile, 2010. p. 175-186.

ILLANES, María Angélica. En el nombre del pueblo, del estado $y$ de la ciencia, (...) Historia social de la salud pública. Chile 1880/1973. (Hacia una historia social del siglo XX). Santiago: Ministerio de Salud, 2010.

JAMESON, Jena; STRAUSS, Neil. Cómo hacer el amor igual que una estrella del porno. España: Martínez Roca, 2005.

LE BRETON, David. Antropología del cuerpo y modernidad. Buenos Aires. 2002.

MONTECINOS, Sonia. Madres y huachos. Alegorias del mestizaje chileno. Santiago: Editorial Sudamericana, 1996.

MONTECINOS, Sonia. Mestizaje. In: SALAS ASTRAIN, Ricardo (org.). Pensamiento crítico latinoamericano: conceptos fundamentales. Santiago: Ediciones Universidad Católica Silva Henríquez, 2005. p. 655-661.

NANCY, Jean Luc. Corpus. Madrid: Arena Libres, 2003.

NEIRA, Hernán. Latinoamérica-Iberoamérica. In: SALAS ASTRAIN, Ricardo (org.). Pensamiento crítico latinoamericano: conceptos fundamentales. Santiago: Ediciones Universidad Católica Silva Henríquez. 2005. p. 585-594.

PRECIADO, Beatriz. Pornotopía. Barcelona: Anagrama, 2010.

PRECIADO, Beatriz. Testo yonqui. Madrid: Espasa-Calpe, 2008.

PRECIADO, Beatriz. La invención del género, o el tecno cordero que devora a los lobos. Disponible en: http://ms.gba.gov.ar/ssps/ residencias/biblio/PreciadoB_Biopolitica_genero.pdf. Acceso en: 07 agosto 2018.

PRECIADO, Beatriz. Manifiesto Contra-Sexual. Barcelona: Opera Prima. 2002.

RICHARD, Nelly. La problemática del feminismo en los años de la transición en Chile. In: CLACSO. Estudios latinoamericanos sobre cultura y transformaciones sociales en tiempos de globalización. Buenos Aires: Consejo Latinoamericano de Ciencias Sociales (CLACSO), 2001. p. 227-239.

SÁNCHEZ, Cecilia. Escenas del cuerpo escindido. Ensayos cruzados de la filosofía, literatura y arte. Santiago: Cuarto Propio/Arcis, 2005. 
SILVA, Víctor; BROWNE, Rodrigo. Antropofagias. Las indisciplinas de la comunicación. Madrid: Nueva Madrid, 2007.

SILVA, Víctor; BROWNE, Rodrigo. Escrituras Híbridas y rizomáticas. Pasajes intersticiales, pensamiento del entre, cultura y comunicación Madrid: Arcibel, 2004.

TAUSSIG, Michael. La bella y la bestia. Antípoda, n. 6, enerojun. 2008, 17-40. Disponible en: https://revistas.uniandes.edu.co/ doi/pdf/10.7440/antipoda6.2008.02. Acceso en: 07 agosto 2018. https://doi.org/10.7440/antipoda6.2008.02

Recibido en: 27/8/2018.

Aprobado en: 7/3/2019.

Publicado en: 25/11/2019.

Dirección postal:

Marcela Carolina Hurtado Rubio

Universidad Austral de Chile (UACh)

Independencia, 631 - Valdivia

Región de los Ríos, Chile

\section{Autores/Authors:}

Marcela Carolina HurTado Rubio marcelahurtado@uach.cl

- Doctora en Ciencias Humanas y Arquitecta, Universidad Austral de Chile (UACh); Profesora e investigadora del Instituto de Artes Visuales de la Facultad de Arquitectura y Artes y Directora del Departamento de Creación Artística, Universidad Austral de Chile (UACh), Independencia 631, Valdivia, Región de los Ríos, Chile. Actualmente lleva a cabo la investigación "Cuerpos en Crisis: Análisis del Discurso corporal en 10 obras de coreógraf@s chilenos entre 1990 y 2010". (D) https://orcid.org/0000-0002-3390-6939

- Doutora em Ciências Humanas e Arquiteta, Universidade Austral do Chile (UACh). Professora e pesquisadora do Instituto de Artes Visuais da Faculade de Arquitura e Artes . Professora e pesquisadora do Instituto de Artes Visuas da Faculade de Arquitetira e Artes e Diretor do Departamente de Cria 631, Valdivia, Região dos Rios, Chile. Atualmente, está realizando a pesquisa "Corps en Crisis: Análise do discurso corporal em 10 ot

- Doctor in Human Sciences and Architect, Austral University of Chile (UACh); Professor and researcher of the Institute of Visual Arts of the Faculty of Architecture and Arts and director of the Department of artistic creation, Austral University of Chile (UACh), Independencia 631, Valdivia, Region of the Rivers, Chile. Currently conducting the investigation "Bodies in Crisis: Analysis of body discourse in 10 works by chilean choreographers between 1990 and 2010".

Rodrigo Francisco Browne SARTORI rodrigobrowne@uach.cl

- Doctor en Comunicación, Universidad de Servilla (US); Profesor e investigador del Instituto de Comunicación Social de la Facultad de Filosofia y Humanidades y Director de Estudios de Postgrado de la Universidad Austral de Chile (UACh), Independencia 631, Valdivia, Región de los Ríos, Chile; Ha publicado recientemente "No al autor. Una revisión desautorizada a la crisis del autor" (2018, Plaza y Valdés, Madrid) y "Semiosis Antropófaga. Semiótica Comunicación y Posestructuralismo" (2018, Ediciones UFRO, Temuco).

(D) https://orcid.org/0000-0001-8945-1059

- Doutor em Comunicação, Universidade de Sevilha (US); Professor e pesquisador do Instituto de Comanicaça Soctor de Estudos de "Vhildivia, Região dos Rios, Chile; Recentemente foi publicado "No al autor, una revisión desautorizada a la crisis del autor" (2018, Plaza y Valdés, Madrid) e "Semiosis Antropófaga, Semiótica Comunicación y Posestructuralismo"
(2018, Edições UFRO, Temuco).

- Doctor of Communication, Seville University (US); Professor and researcher at the Institute of Social Communication of the Faculty of Philosophy and Humanities and Director of Postgraduate Studies at the Austral University of Chile (UACh), Valdivia, Region of the Rivers, Chile. There has recently been published "No al autor, Una revisión desautorizada a la crisis del autor" (2018, Plaza y Valdés, Madrid) and "Semiosis Antropófaga, Semiótica Comunicación y Posestructuralismo" (2018, UFRO Editions, Temuco). 